\title{
Giant Pulmonary Chondroid Hamartoma in Welder's Lung: A Unique Case Report
}

\author{
Abdul Rasheed Qureshi ${ }^{1,2}$, Huma Bilal ${ }^{3}$, Muhammad Sajid ${ }^{3}$ \\ ${ }_{1}^{1}$ Pulmonologist, Gulab Devi Teaching Hospital Lahore, Pakistan \\ ${ }^{2}$ Director, Institute of Biotechnology, Gulab Devi Educational Complex Lahore, Pakistan \\ ${ }^{3}$ Medical Officer, Gulab Devi Teaching Hospital Lahore, Pakistan
}

\begin{abstract}
A B S T R ACT
Pulmonary Hamartomas are benign lung tumors, containing cartilage, connective tissue, fat and usually appear as peripheral lesions. They are $2-4 \mathrm{~cm}$ in size, frequently asymptomatic, comprising of $5-8 \%$ of all solitary pulmonary nodules. The peak incidence occurs in 40-70 years of age with a male preponderance. We describe a unique case of centrally located, giant chondroid hamartoma, in the background of pulmonary hemosiderosis. Patient presented with cough, shortness of breath and left sided chest pain, masquerading as pleural effusion, lung cancer and left sided chest pain mimicking myocardial disease. Chest x-ray raised the suspicion of pleural effusion but ultrasound and CT-scan indicated a benign calcified central mass. A presumptive diagnosis of cartilage-containing benign mass was made on ultrasound-guided percutaneous biopsy, while surgical resection followed by histopathology revealed a chondroid hamartoma. No recurrence was noted on follow-up. Chondroid hamartoma can be large, symptomatic and requires modern modalities for diagnosis while its association with pulmonary hemosiderosis, still requires to be investigated.
\end{abstract}

Key Words: Benign lung tumor, Pulmonary chondroid hamartoma, Welder's Lung

$\begin{array}{ll}\text { Correspondence: } & \text { Article info: } \\ \text { Abdul Rasheed Qureshi } & \text { Received:August 12, 2020 } \\ \text { Email:drrasheed57@gmail.com } & \text { Accepted: September 10, 2020 }\end{array}$

Cite this case Report: Qureshi AR, Bilal H, Sajid M. Giant Pulmonary Chondroid Hamartoma in $\quad$ Funding Source: Nil Welder's Lung - A Unique Case Report. J Islamabad Med Dental Coll. 2020; 9(3): 219-224. Doi: $\quad$ Conflict of Interest: Nil 10.35787/jimdc.v9i3.584

\section{Introduction}

Hamartoma is defined as a focal lesion, consisting of normal cells at normal site but with faulty arrangement, simulating a tumor. Organ architecture is not preserved inside the lesion. ${ }^{1}$ Pulmonary Hamartoma was first described by Albrecht in 1904. Goldsworthy in 1934, defined it as a benign tumor of lung composed, predominantly of a combination of fat and cartilage. ${ }^{2}$ Pulmonary hamartoma has an estimated incidence of 0.025$0.032 \%$ and constitutes about $5-8 \%$ of all solitary pulmonary nodules. ${ }^{3}$ The hamartoma usually appears rounded with well-defined margins. Solitary nodules are commonly encountered in males with peak incidence in 40-70 years, while multiple pulmonary lesions are found in females. ${ }^{4}$ If cartilage tissue predominates, it is termed as chondroid hamartoma, which are only $1 \%$ of all pulmonary hamartomas. ${ }^{5}$ The size usually ranges from 1 to $4 \mathrm{~cm}$ with average size of $2 \mathrm{~cm}$. Majority of the lesions arise from connective tissue in the peripheral lung parenchyma, with only $10 \%$ originating from the lining of the bronchi. ${ }^{6}$ Most hamartomas show slow 
annual growth and patients are asymptomatic, but some may grow rapidly and exhibit malignant transformation. ${ }^{7}$ Most patients are detected incidentally on $\mathrm{x}$-ray chest or autopsy. Symptomatic hamartomas demand for a thorough diagnostic approach, and surgical resection. Precise etiology is not known but evidence from cytogenetic analysis points towards recombination of chromosomal bands. ${ }^{8}$

\section{Case Report}

Our patient was a 63 years old male, five feet eight inches tall, and weighing $74 \mathrm{Kg}$. He has been associated with gas and electric arc welding profession for the last forty-five years. He also gave history of cigarette smoking for the past 45 years ( 55 pack-years), but now has quit smoking in the last two months. He had no history of any other addiction. Patient is married with six issues, all alive and healthy. His father suffered from chronic obstructive pulmonary disease (COPD). There was no history of bronchial asthma, diabetes mellitus, hypertension, ischemic heart disease or cancer in the family.

The patient presented with cough (1.5 years duration), shortness of breath (10 months duration), left-sided chest pain (for the last 6-7 month) and epigastric burning ( 6 months duration), which was relieved temporarily by various antacids. The cough was not associated with fever, hemoptysis, hoarseness of voice, nasal blockage or any ear problem.

According to the patient, shortness of breath was mild initially and responded temporarily to medications from local practitioners. It worsened with heavy work, but was not associated with tachycardia, palpitation, syncope attacks, orthopnea or swelling of feet. It progressed gradually to Grade 2 of Modified Medical Research Council (mMRC) Dyspnea Scale during the last few months.
Patient also complained of left-sided chest pain for the last six months. Pain was dull, continuous and exacerbated with cough or heavy work. It was localized to the back-middle and front-lower aspect of the chest, for which he had to take pain killers off and on. Eight years back, patient was treated for pulmonary tuberculosis with a full course of anti-TB drugs for a period of six months. There was no past history of any surgical procedure.

On physical examination pulse was $82 / \mathrm{min}$, blood pressure $130 / 80 \mathrm{mmHg}$, temperature $98^{\circ} \mathrm{F}$ and respiratory rate was $26 / \mathrm{min}$. Respiratory system findings included abdominothoracic respiration, elliptical chest with a vague bulge on the posterolateral aspect of the left lower chest. Chest movements and chest expansion were decreased on the left side. Percussion note was dull and air entry was reduced on the left side. Crackles and rhonchi were auscultated on both sides of the chest, predominantly on the left side in middle and lower part, while no pleural rub was appreciated. Differential diagnosis of pleural effusion, left lung mass, myocardial disease, chronic obstructive pulmonary disease (COPD) and gastro-esophageal reflux disease (GERD) were considered.

X-ray chest PA view showed an opacity in left lower lung field, obscuring cardiac and diaphragmatic silhouette and obliterating left costophrenic angle, raising the suspicion of pleural effusion and lung mass. Transthoracic ultrasonography ruled out pleural effusion and a solid mass measuring $12 \mathrm{~cm} x$ $8 \mathrm{~cm}$, containing internal calcifications was noted on the left side (Figure 1). High-resolution computed tomography (HRCT) thorax reported a calcified left lung mass along with features of pulmonary hemosiderosis (Figure 2). Ultrasound guided transthoracic tru-cut needle biopsy suggested the diagnosis of a hamartoma or teratoma and excisional biopsy was advised for further evaluation.

Two sputum sample were tested for acid-fast bacilli (AFB) by fluorescent microscopy to rule out 
tuberculosis. Hematological results were unremarkable (Table I).

Table I: Hematological and Biochemical tests

\begin{tabular}{|c|c|c|}
\hline Test & Result & Reference Value \\
\hline \multicolumn{3}{|l|}{ Hematological tests } \\
\hline Hemoglobin & 12.8 & $13-18 \mathrm{~g} / \mathrm{dl}$ \\
\hline ESR & 45 & 1-10 mm1st Hour \\
\hline WBC & 8.700 & $4-11 \times 10^{3} / \mu \mathrm{L}$ \\
\hline RBC & 4.1 & $4.5-6.5$ \\
\hline HCT & 32 & $40-54 \%$ \\
\hline MCV & 78 & $76-96$ \\
\hline $\mathrm{MCH}$ & 28 & $27-32 p g$ \\
\hline $\mathrm{MCHC}$ & 35 & $30-35 \mathrm{~g} / \mathrm{dl}$ \\
\hline Platelets & 175 & $150-450 \times 10^{3} / \mu \mathrm{L}$ \\
\hline Polys & $60 \%$ & $40-75 \%$ \\
\hline Lymphocytes & $35 \%$ & $20-45 \%$ \\
\hline Monocytes & $3 \%$ & $2-10 \%$ \\
\hline Eosinophils & $2 \%$ & $1-6 \%$ \\
\hline \multicolumn{3}{|l|}{ Biochemical Tests } \\
\hline Serum Bilirubin & 1.0 & $0.2-1.1 \mathrm{mg} / \mathrm{dl}$ \\
\hline SGOT (AST) & 31 & $5-45 \mu / d l$ \\
\hline SGPT(ALT) & 27 & $5-42 \mu / d l$ \\
\hline $\begin{array}{l}\text { Alkaline. } \\
\text { Phosphatase }\end{array}$ & 257 & $100-270 \mu / \mathrm{dl}$ \\
\hline Serum Protein & 6.8 & $6-8 \mathrm{~g} / \mathrm{dl}$ \\
\hline Urea & 42.0 & $10-50 \mathrm{mg} / \mathrm{dl}$ \\
\hline Serum Creatinine & 1.1 & $0.5-1.4 \mathrm{mg} / \mathrm{dl}$ \\
\hline Sodium level & 142 & $135-155 \mathrm{mmol} / \mathrm{L}$ \\
\hline Potassium level & 3.5 & $3.4-5.5 \mathrm{mmol} / \mathrm{L}$ \\
\hline $\begin{array}{l}\text { Blood Sugar } \\
\text { Random }\end{array}$ & 124 & $80-160 \mathrm{mg} / \mathrm{dl}$ \\
\hline TIBC & 542 & $250-450 \mu \mathrm{g} / \mathrm{dl}$ \\
\hline Serum Ferritin level & 24.66 & $38-457 \mathrm{ng} / \mathrm{ml}$ \\
\hline $\mathrm{HBs} \mathrm{Ag}$ & Negative & Negative \\
\hline Anti HCV & Negative & Negative \\
\hline
\end{tabular}

ECG and echocardiography were reported normal. Pulmonary function test (PFT) revealed moderately severe restriction. Bronchoscopy displayed hypervascular mucosa of main bronchial tree and compression from outside of the left main and lower lobar bronchus but no endobronchial mass or foreign body was noted. Trans-abdominal ultrasonography showeda $2.2 \mathrm{~cm}$ echogenic focus in the right lobe of liver with an impression of hemangioma. Metallic depositions were noted in splenic and renal parenchyma (Figure 2).

The patient underwent left posterolateral thoracotomy and a $14 \mathrm{~cm} \times 10 \mathrm{~cm}$ rounded mass, adherent to lung, pericardium and diaphragm was excised in toto and bronchial communication was noted. Cut-surface of the mass was grey-white and gritty. Histopathology revealed a cartilaginous neoplasm composed of islands of normal cartilage, fibro-adipose tissue with intervening clefts, lined by ciliated respiratory epithelium and finally diagnosed as Chondroid Hamartoma. Postoperativex-ray chest showed complete lung expansion. No residual or recurring tumor was found on follow-up CT scans. Pulmonary function tests returned to normal indicating that objective of the surgery has been achieved. Patient had an uneventful follow-up nine months after surgery.

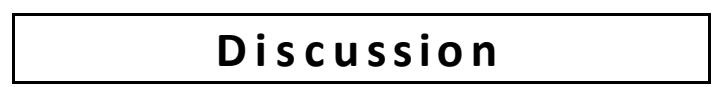

This 63-year-old, male patient, diagnosed as chondroid hamartoma is well justified because of age and gender. Most of the hamartomas are small in size $(2.0-4.0 \mathrm{~cm})$ but this lesion with a size of 14 $\mathrm{cm} \times 10 \mathrm{~cm}$ is an uncommon finding. These tumors are usually asymptomatic while our patient presented with an array of symptoms, compromising his pulmonary functions, for which he had to take treatment from various physicians, time and again. On the grounds of history and physical examination findings, this case was initially misdiagnosed as pleural effusion, lung cancer and myocardial disease, making the case atypical. The presence of chondroid hamartoma on the background of pulmonary hemosiderosis is a unique feature, while there is scarcity of medical literature regarding the question of association between the two conditions. The frequency of the tumor ( $1.0 \%$ of all pulmonary hamartomas) additionally, indicates its rare nature. 


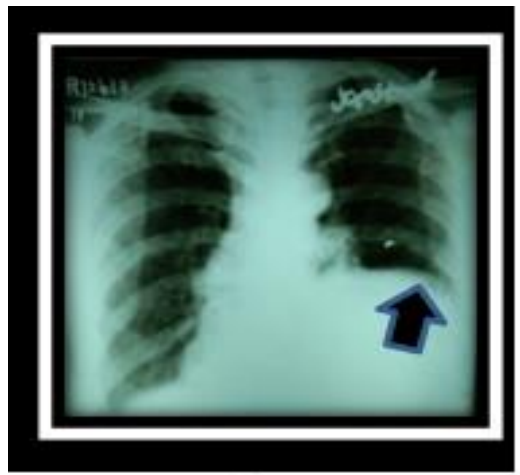

A

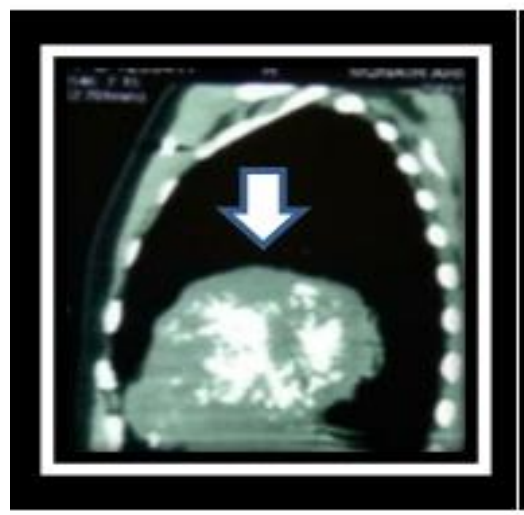

D

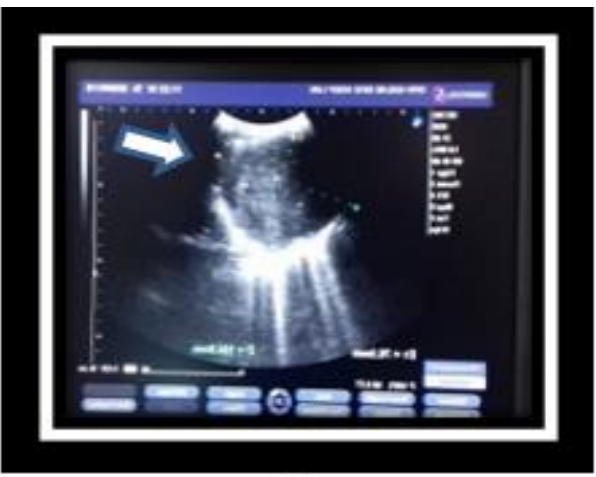

B

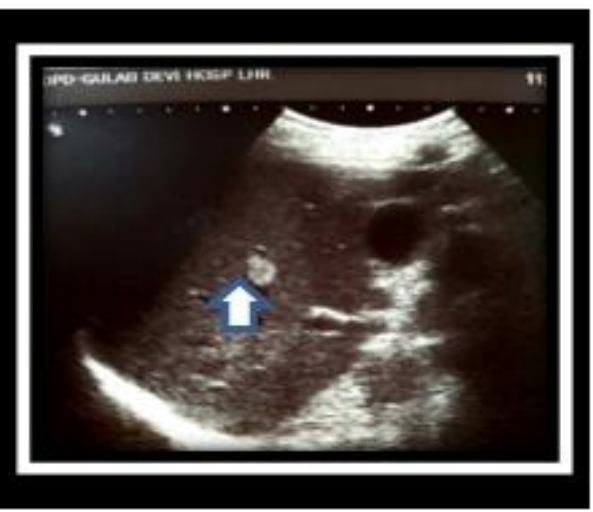

E

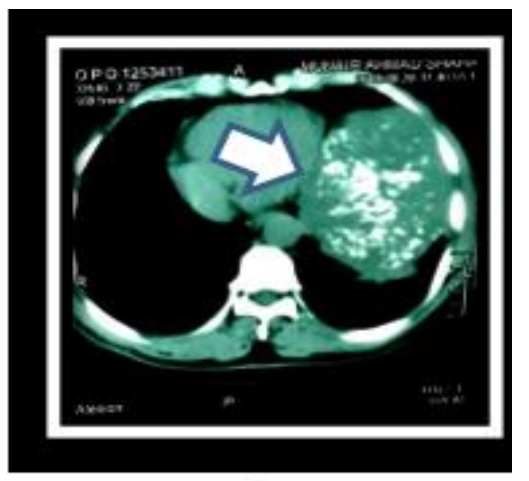

C

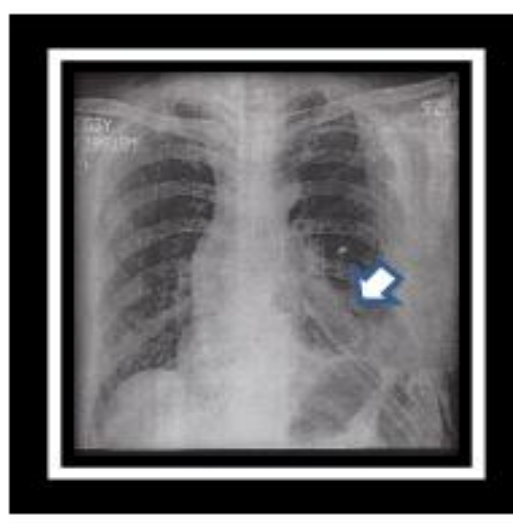

$\mathbf{F}$

Figure 1: Radiology of Hamartoma. A. X-ray chest (PA view) showing suspicion of pleural effusion/mass left side. B. Ultrasonographic image showing a solid mass with internal calcifications. C \& D. HRCT-image showing well-defined rounded mass with pop-corn calcification. E. Ultrasonographic image of a hemangioma in the right lobe of liver. $F$. Xray chest (PA view) showing complete lung expansion after surgery and chest drain in situ

This neoplasm has a slow growth rate while recurrence and malignant transformation are extremely unusual. ${ }^{9}$ In this case, the lesion has acquired a size of $14 \mathrm{~cm}$ within a period of eight years. There was no evidence of the tumor eight years back when he was treated for pulmonary tuberculosis, indicating a comparatively rapid growth rate. Older age, history of heavy smoking and hemosiderosis further added to the suspicion of a malignant process. ${ }^{10,11}$ Transcutaneous needle biopsy ruled out malignancy.

Similarly, a centrally located hamartoma, compressing left main and lower lobe bronchus is also a quite unexpected feature, because over $90 \%$ of these lesions occur in a peripheral location. ${ }^{12}$
Risk factors of older age, 55-pack years of cigarette smoking and left-sided chest pain, raised the suspicion of myocardial disease, but ECG and Echocardiography ruled out any cardiac problem.Xray chest and physical examination suggested pleural effusion, but transthoracic ultrasound indicated a mass lesion with internal calcification (Figure 1), reflecting the usefulness of chest ultrasound. HRCT described it as a calcified mass. CT scan further reported the presence of multifocal metallic deposition (Figure 1) leading to the diagnosis of pulmonary hemosiderosis and highlighting the precision of HRCT. Metallic deposition was noted in the subcutaneous tissue, hilum, around great vessels of neck, lung, mediastinum, pericardium, spleen and left kidney (Figure 2). 


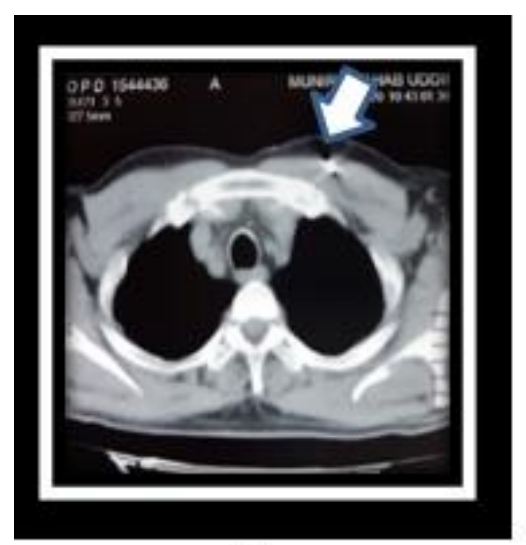

A

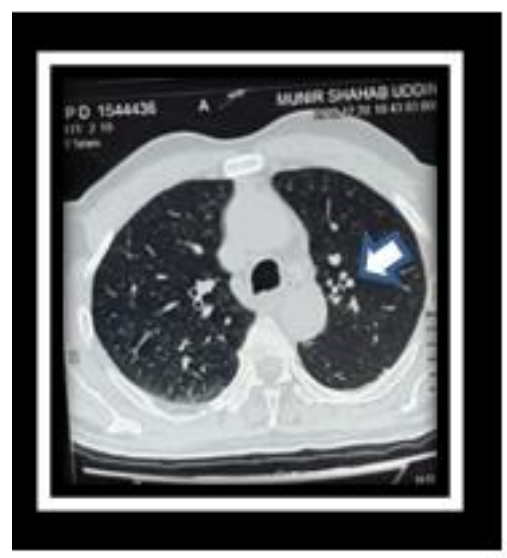

D

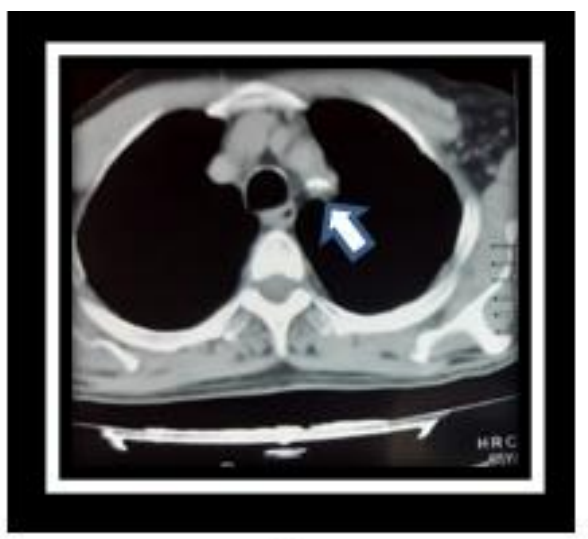

B

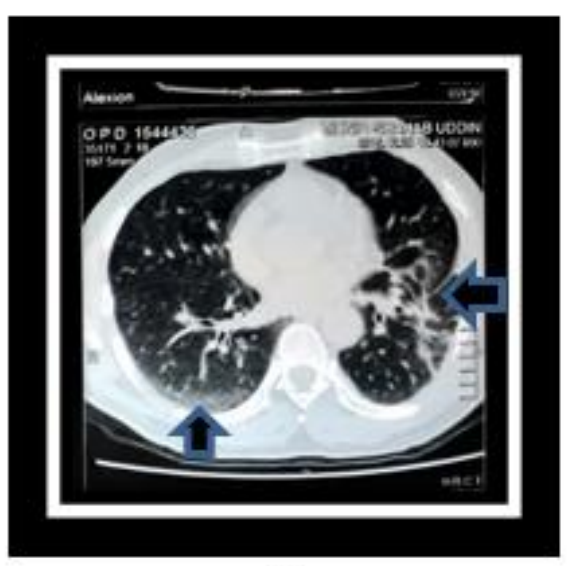

$\mathbf{E}$

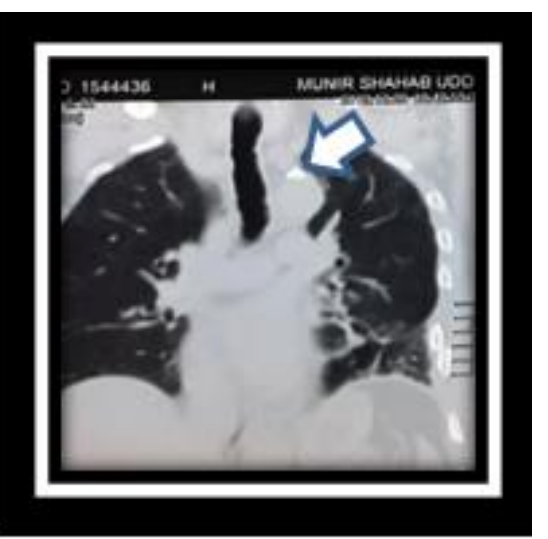

C

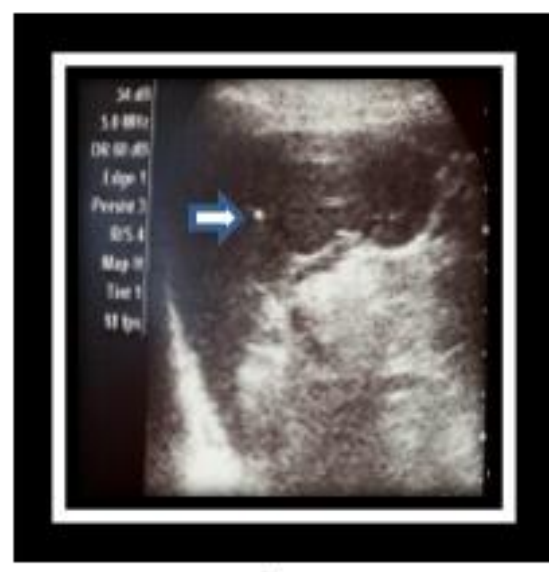

$\mathbf{F}$

Figure 2: Radiological signs of hemosiderosis. A. Sub-cutaneous metallic deposition. B. Mediastinal metal deposition. C. Metal deposited around great vessel. D. Metal deposition within the lung. E. Signs of bronchiectasis and ground glass appearance secondary to hemosiderosis. F. Metal deposition within splenic parenchyma

Bronchoscopy was performed to rule out the possibility of concurrent endobronchial hamartoma. While abdominal ultrasound revealed a $2.2 \mathrm{~cm}$ hemangioma, in right lobe of liver (Figure 1). Very rarely, hamartoma become aggressive after surgery, so a follow-up was done at three-month interval and patient remained uneventful up to nine months after surgery.

The presentation of a giant, central, rapidly growing, benign hamartoma on the background of Welder's Lung is actually the unique feature of this case. There is dearth of literature regarding the question of association between the two pathologies. Further work up is required to explore this phenomenon.

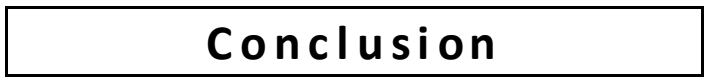

This case is reported because of its unique features of a central chondroid hamartoma, associated with pulmonary hemosiderosis, masquerading as pleural effusion, lung cancer and myocardial disease. Modern modalities like ultrasound, CT-scan and invasive procedures combined with histopathology can unfold the mystery. Furthermore, excisional surgery is curative for symptomatic patients, capable of restoring the normal lung functions. 


\section{References}

1. Leiter HF, Restrepo CS, Alvarez Gómez DI, Suby-Long T, Ocazionez D, Vargas D. Hamartomas from head to toe: an imaging overview. Br J Radiol. 2017 Mar; 90(1071):20160607. Doi: 10.1259/bjr.20160607

2. Hua X., Huang X., Liao Z, Xian Q, Yu L. Clinicopathological and EBV analysis of respiratory epithelial adenomatoid hamartoma. Diagn Pathol. 2014; 9: 70. Doi: 10.1186/1746-1596-9-70

3. Rajasekhar S, Patnayak R, Kale PG, Chandra A, Jena A. A case of solitary pulmonary nodule (large pulmonary chondroid hamartoma). Med J DY Patil Univ. 2016; 9(6): 744-6. Doi: 10.4103/0975-287 0.19 4203

4. Fan $M$, Lin $Y$, Liu L. Multiple pulmonary chondroid hamartoma. J Thorac Oncol. 2014; 9(7): 1053-1054. Doi:10.1097/JTO.0000000000000175

5. Itoga M, Kobayashi Y, Takeda M, Moritoki Y, Tamaki M, Nakazawa $K$, et al. A case of pulmonary hamartoma showing rapid growth. Case Rep Med. 2013; 2013: 231652.

6. Ahmed S, Arshad A, Mador MJ. Endobronchial hamartoma; a rare structural cause of chronic cough. Respir Med Case Rep. 2017; 22: 224-227. Doi: 10.10 16/j.rmcr.2017.08.019

7. Byoung Jun L, Hye-Ryoun K, Gi Jeong C, Jae Soo K, Cheol Hyeon K, Jae Cheol L, et al. Squamous Cell Carcinoma arising from Pulmonary Hamartoma. Clin
Nucl Med. February 2011; 36(2): 130-131. Doi: 10 $.1097 / R L U .0 b 013 e 318203 b c 27$

8. Sylvain T, Johnson E, Michele R, Fausto R, MarieChristine A, John C, et al. Formation of the 12q14-q15 Amplicon Precedes the Development of a Welldifferentiated Liposarcoma Arising From a nonchondroid Pulmonary Hamartoma. The Am J Surg Pathol. October 2006; 30(10): 1326-9. Doi: 10.1097/01.pas.0000213257.69478.2f

9. Saadi MM, Barakeh DH, Husain S, Hajjar WM. Large multicystic pulmonary chondroid hamartoma in a child presenting as pneumothorax. Saudi Med J. 2015; 36(4): 487-9. Doi: 10.15537/smj.2015.4.10210

10. Zheng M, Marron RM, Sehgal S. Hard Metal Lung Disease: Update in Diagnosis and Management. Curr Pulmonol Rep. 2020; 9: 37-46. Doi: 10.1007/s13665020-00247-x

11. Liu C, Wang J, Zhu Y, Chen C. Successful use of snare electrocautery via flexible fiberoptic bronchoscopy for removal of an endobronchial hamartoma causing chronic lung atelectasis and mimicking malignancy. Ther Adv Respir Dis. 2017; 11(12): 435-8. Doi: 10.1177/1753465817736745

12. Kishore M, Gupta P, Preeti, Deepak D. Pulmonary Hamartoma Mimicking Malignancy: A Cytopathological Diagnosis. J Clin Diagn Res. 2016; 10(11): ED06-ED07. Doi: 10.7860/JCDR/2016/22597 .8844 . 